\title{
Team-based learning: Application in undergraduate baccalaureate nursing education
}

\author{
Sandy Branson , Lisa Boss, Debra L. Fowler \\ School of Nursing, University of Texas Health Science Center, Houston, TX, United States
}

Received: September 23, 2015

Accepted: December 2, 2015

Online Published: December 15, 2015

DOI: $10.5430 /$ jnep.v6n4p59

URL: http://dx.doi.org/10.5430/jnep.v6n4p59

\begin{abstract}
Objective: The aim of the study was to determine the efficacy of Team-based Learning (TBL) in an undergraduate nursing course with regard to the outcomes of academic performance (Health Education Systems Incorporated [HESI ${ }^{\mathrm{R}}$ ] Management exam) and self-reported measures of critical thinking, leadership and management skills, overall course ratings, accountability to learning, preference for lecture or TBL, and learner satisfaction with TBL.

Methods: In a quantitative, quasi-experimental post-test study, 221 undergraduate senior nursing students participated in the TBL course or a traditional instructor-led control course. In both courses, academic performance was measured by the HESI ${ }^{\circledR}$ Management scores; critical thinking, leadership and management skills, and overall course experience were measured using an online survey. In the TBL course, accountability to learning, preference for lecture or TBL, and learner satisfaction was measured with the Team-Based Learning Student Assessment Instrument.

Results: When compared to lecture, TBL learners scored significantly higher on the HESI ${ }^{\circledR}$ Management exam and reported significantly higher critical thinking, leadership and management skills and better overall course experience ratings $(p \leq .01)$. TBL learners reported moderate to high levels of accountability, higher preference for TBL than lecture, and satisfaction with TBL. Total scores indicated moderate to high levels of favorable experiences with TBL.

Conclusions: Results indicate TBL is an acceptable and efficacious instructional strategy in undergraduate nursing students. To control for extraneous factors and limit confounding, future research should evaluate the impact of TBL via a randomized control trial.
\end{abstract}

Key Words: Team-based learning, Nursing education, Leadership, Management

\section{INTRODUCTION}

The United States health care delivery system is undergoing change at a rapid pace. Various factors are influencing change including modifications to the system as prescribed by the Patient Protection and Affordable Care Act (2010). ${ }^{[1]}$ One of these changes is a strategic emphasis on inter-professional collaboration and team-based care. Global perspectives increasingly influence US health care; the World Health Organization (WHO, 2010) has also linked effective collaboration and improved health outcomes and stressed the need for education. ${ }^{[2]}$

The rapidly evolving team-based care environment has created a need for change in nursing practice and education. Benner, Sutphen, Leonard, and Day (2010) ${ }^{[3]}$ assert that nursing educational programs and practices must undergo radical transformation. National organizations ${ }^{[4]}$ and nursing education leaders ${ }^{[5]}$ have called for a transition away from traditional teacher-focused education methods to ac-

\footnotetext{
*Correspondence: Sandy Branson; Email: sandra.m.branson@uth.tmc.edu; Address: School of Nursing, University of Texas Health Science Center, Houston, TX, United States.
} 
tive, learner-centered instruction. Others have specifically called for teaching effective communication and collaboration skills that prepare learners for the dynamic, team-based care environment. ${ }^{[6,7]}$ Nurse educators must use teaching methodologies that go beyond a traditional classroom lecture on teamwork to active learning strategies that foster open communication and shared decision-making, hallmarks of effective collaboration.

\subsection{Team communication and collaboration in health- care delivery}

A growing body of knowledge has linked cooperative, team-based care with better patient and family satisfaction outcomes, according to the groundbreaking Institute of Medicine report, The Future of Nursing: Leading Change, Advancing Health. ${ }^{[8]}$ The report emphasizes that teaching effective communication and shared decision-making skills to all health professions learners is paramount to accomplishing team-based care. Two key national nursing excellence recognition programs, the American Nurses Credentialing Center's Magnet Recognition Program ${ }^{\circledR}(2014)^{[9]}$ and the American Association of Critical Care Nurses' Beacon Award for Excellence (2010), ${ }^{[10]}$ identified effective communication and collaboration as one of the healthy work standards influencing positive patient outcomes.

\subsection{Team-based learning}

The team-based learning (TBL) approach was created forty years ago by Dr. Larry Michaelsen as a method to facilitate classroom participation with a large number of learners. ${ }^{[1]}$ Since its beginning, TBL has been used successfully in various professional disciplines, including business, law, engineering, medicine, and nursing. Published evidence indicates that nurse educators are using TBL in response to calls from national nursing leaders, the American Association of Colleges of Nursing, the National Council of State Boards of Nursing, and the National League for Nursing to incorporate learner-centered and evidenced-based instructional strategies in undergraduate nursing education. ${ }^{[12]}$

The process of TBL involves a specific sequence of pre-class activities, individual and group work in the classroom, and immediate feedback. This teaching model creates a motivational framework in which learners are responsible to one another to prepare before class and contribute to the learning experience. ${ }^{[12]}$ Mennenga and Smyer (2013) provide a clear model for implementing TBL in a nursing course. ${ }^{[12]}$ Faculty members provide readings and other instructional material for learners to study before class. At the beginning of the class, learners take an Individual Readiness Assurance Test (IRAT) followed by a Group Readiness Assurance
Test (GRAT). Small groups of 5 to 7 learners are formed at the beginning of the semester and continue to work together throughout the course. Typically, both test scores are included in the course grade calculation; faculty determines the relative weight of each test. After the IRAT and GRAT, groups work on activities that are designed to enhance their understanding of the course content. The activities should present a significant problem that learners must solve and determine a specific choice. ${ }^{[11]}$ All groups share their choice simultaneously; this stimulates discussion among the learners as they defend their choice and delineate their critical thinking process. ${ }^{[11]}$

In a systematic review of TBL studies, Sisk $(2011)^{[13]}$ found that analyses of learner outcomes focused on learner satisfaction, learner engagement, and examination grades. Learners were satisfied with the active style of learning but some preferred the passive conventional lecture. Engagement was generally higher with TBL than with other teaching methods. Researchers found that examination scores were higher with TBL but often did not provide adequate information about the nature of the exams. The author recommended that standardized exams, such as the Health Education Systems Incorporated (HESI ${ }^{\circledR}$ ) exam, could be used to measure learning at the end of the course. Additionally, the author found that lower performing learners benefited from TBL to a greater extent than their higher performing peers. In a nursing ethics course, Hickman and Wocial (2013) found that the TBL model worked well to teach moral competence, specifically moral perception, moral judgment, and moral behavior. Not only did the learners acquire knowledge of these concepts, but they also experienced them in the group interactions required in the TBL model.

\subsection{Objectives}

The aim of the study was to determine the efficacy of TBL in a required undergraduate nursing leadership and management course with regard to the outcomes of academic performance (HESI ${ }^{\circledR}$ Management exam) and self-reported measures of critical thinking, leadership and management skills, overall course ratings, accountability to learning, preference for lecture or TBL, and learner satisfaction with the TBL. The hypothesis was that learners in the TBL course would have significantly higher exam scores than learners in the instructor-led, lecture-based course and would report higher levels of critical thinking, development of leadership and management skills, and better overall course experiences. In addition, the authors hypothesized that learners in the TBL course would report high levels of accountability, a preference for TBL, and satisfaction with the TBL approach. 


\section{MeTHODS}

\subsection{Design}

A quantitative, quasi-experimental post-test design was used for this study. The instructor-led course (control) was conducted in spring 2014, and the TBL course was conducted in summer 2015.

\subsection{Sample}

The study included 221 undergraduate senior nursing students who were enrolled in a 3-credit-hour required professional practice course. The TBL class comprised 102 learners, and the traditional instructor-led control class comprised 119 learners. Based on a meta-analysis ${ }^{[14]}$ that compared collaborative learning methods versus traditional lecture-based methods on academic outcomes and reported an effect size of 0.60 , a conservative effect size was selected for the current study. Power analysis indicated a total sample size of $\mathrm{N}=128(\mathrm{n}=64$ per group) was found to yield statistical power $>80 \%$ with two-tailed independent samples $t$-test for a medium effect size (Cohen's $d=.50$ ) with the desired type I error set at 0.05 using the $\mathrm{G}^{*}$ Power 3.17 program.

\subsection{Setting and recruitment}

Participants were recruited from a state-funded, baccalaureate nursing school in a major metropolitan city in the southern United States. In the TBL course, participants were invited to complete the TBL Student Assessment Instrument (TBL-SAI) online survey at the end of the course. Faculty members explained that completion of the survey was voluntary and would not affect learners' course grade. For recruitment purposes, learners who completed the TBL-SAI were entered in a drawing for a $\$ 20$ gift card.

\subsection{Procedures}

The instructor-led lecture course (spring 2014) comprised traditional instructor-led lecture using PowerPoint presentations. The TBL course (summer 2015) consisted of pre-class preparation (reading assignments) and a readiness assurance process during class that included individual tests followed by team tests and discussion, mini-lecture, and team application case studies. The same faculty members delivered both courses using the same content. Faculty members were formally trained using the TBL approach and had piloted and refined the TBL course the two previous semesters.

In the TBL course, learners were oriented to TBL on the first day of class. Permanent group allocation occurred by randomization of 5-7 learners per team, by drawing numbers from a bag. Faculty members then redistributed team membership with the intent to equalize gender and previous leadership and health care experience in the groups. A team

Published by Sciedu Press leader was then elected by each group. The preparation process of Phase 1 included pre-assigned reading with guided PowerPoint presentations provided before class (see Figure 1). The readiness assurance process in Phase 2 included an in-class closed-book IRAT comprising a 10-item multiple choice test in the university's learning management system. The IRAT was worth $6 \%$ of the course grade.

Following the IRAT, the team discussed and answered the same questions as the IRAT and reported answers for the GRAT using an Immediate Feedback Assessment Technique (IF-AT ${ }^{\circledR}$ ) self-scoring answer sheet, ${ }^{[15]}$ a process that was also closed-book. The GRAT was worth $9 \%$ of the course grade. The multiple choice tests were designed to test concepts and ideas that would solve the case studies that were used in the application exercises ${ }^{[16]}$ and content specific to the $\operatorname{HESI}^{\mathrm{R}}$ Management exam.

After the GRAT was completed, TBL team leaders simultaneously held up signs indicating the team's answer for each question. Faculty members noted when the team answers were incorrect, which prompted faculty feedback to clarify misperceptions and facilitate team discussions. Learners were allowed to appeal a test item, using evidence-based data and submit it to faculty within 48 hours.

After faculty feedback and team discussion, Phase 3 included a team-based real-world case study assignment that was applicable to the content and important to the learners. ${ }^{[11]}$ The same case study was used for all teams and an answer to an important clinical scenario was required with teams reporting their specific choices. ${ }^{[11]}$ Faculty also facilitated open-ended questions with intra-and inter-team discussions that were applicable to the case study. At the end of the semester, learners anonymously assigned individual team members a score based on their perceived contribution to the team process. The team member's score was worth $5 \%$ of the course grade.

\subsection{Data collection}

Basic demographic information was collected from the university's enrollment database. Data were collected from the instructor-led control group at the end of the spring 2014 semester. Data from the TBL course were collected at the end of the summer 2015 semester. Both groups of learners were required to complete the HESI ${ }^{\circledR}$ Management exam and had the option to complete the anonymous end-of-the-semester course evaluation surveys that measured critical thinking, leadership and management skills, and overall course experience. In addition, TBL learners had the option to complete the end-of-semester anonymous online survey that measured accountability to learning, preference for lecture or TBL, 
and learner satisfaction with the TBL approach. Prior to the study, the university Institutional Review Board granted the project exempt from review.

\subsection{Instruments}

Academic performance was measured using the HESI ${ }^{\circledR}$ Management exam scores administered at the end of the semester. The HESI ${ }^{\circledR}$ Management exam is a 50-item specialty exam provided by Elsevier which is generally accepted as predictive in passing the management portion of the $\mathrm{Na}$ tional Council Licensure Examination-RN ${ }^{\circledR}$.

Critical thinking, leadership and management skills, and overall course experience were measured using an anonymous end-of-semester course evaluation survey. The survey used a 5-point Likert scale (0-4) and asked learners to rate whether "the course engaged critical thinking", to rate whether the "course helped develop competencies in specific skills", and to "rate the overall course experience".

Accountability to learning, preference for lecture or TBL, and learner satisfaction with the TBL approach was measured with the TBL class using an online anonymous Survey Monkey of the TBL-SAI a 39-item instrument using a 5-point Likert scale with responses ranging from strongly disagree to strongly agree. ${ }^{[17]}$ The TBL-SAI includes three subscales: accountability (8-40 points), preference for TBL or lecture (16-80 points), and satisfaction with TBL (9-45 points) with higher scores indicating higher agreement. The total score ranges from 33 to 165 points. The TBL-SAI demonstrates acceptable levels of validity and reliability. ${ }^{[17]}$ In the current study, Cronbach's $\alpha$ was 0.88 .

\begin{tabular}{|c|c|c|c|}
\hline $\begin{array}{c}\text { Phase 1 } \\
\text { Preparation } \\
\text { (Pre-class) }\end{array}$ & \multicolumn{2}{|c|}{$\begin{array}{c}\text { Phase 2 } \\
\text { Readiness Assurance } \\
\text { (In-class) }\end{array}$} & $\begin{array}{c}\text { Phase 3 } \\
\text { Application } \\
\text { (In-class) }\end{array}$ \\
\hline Individual Study & $\underset{\text { Group }}{\mid}$ & $\begin{array}{l}\text { Instructor } \\
\text { Feedback } \\
\text { Team Appeals }\end{array}$ & $\begin{array}{l}\text { Small Group } \\
\text { Assignments }\end{array}$ \\
\hline
\end{tabular}

Figure 1. The three phases of TBL

\subsection{Data analysis}

Data were analyzed using IBM SPSS Statistical Package v. 20 (Research Triangle Park, NC). Descriptive statistics were generated for basic demographic information. Differences in HESI ${ }^{\circledR}$ Management exam scores, critical thinking, leadership and management skills, and overall course experience were analyzed using an independent $t$-test. Accountability for learning, preference for lecture or TBL, and learner satisfaction were measured by summing the subscale scores and total scores and calculating standard errors. A priori statistical significance was set at $p<.05$ for all tests.

\section{Results}

\subsection{Descriptive data}

The instructor-led lecture course included 119 (54\%) learners, and the TBL course included 102 (46\%) learners (see Table 1$)$. The majority of participants were female $(78 \%)$ and white $(43 \%)$, with a mean age of 28 years. All 221 learners completed the HESI ${ }^{\circledR}$ Management exam, 61 learners completed the end-of-semester course evaluations, and 43 learners in the TBL course completed the TBL-SAI.
Table 1. Characteristics of the participants $(\mathrm{N}=221)$

\begin{tabular}{lll}
\hline & Spring 2014 & Summer 2015 \\
& $\mathbf{N}=\mathbf{1 1 9}$ & $\mathbf{N}=\mathbf{1 0 2}$ \\
\hline \multirow{2}{*}{ Age } & $\mathrm{M}=28.1$ years & $\mathrm{M}=28$ years \\
& $(\mathrm{SD}=7.07)$ & $(\mathrm{SD}=6.26)$ \\
Gender & Males $=19$ & Males $=16$ \\
& Females $=86$ & Females $=86$ \\
& Caucasian $=50$ & Caucasian $=45$ \\
Ethnicity & Hispanic $=27$ & Hispanic $=23$ \\
& Black $=11$ & Black $=12$ \\
& Asian $=15$ & Asian $=14$ \\
Missing Data & Other $=2$ & Other $=8$ \\
\hline
\end{tabular}

Note. $\mathrm{M}=$ Mean, $\mathrm{SD}=$ standard deviation

\subsection{Academic and self-reported scores}

Compared with learners in the lecture-based course, learners in the TBL course scored significantly higher on the HESI ${ }^{\circledR}$ Management exam and reported significantly higher degrees of critical thinking and leadership and management skills and better overall course experience ratings (see Table 2). TBL learners who completed the TBL-SAI reported moderate to 
high levels of accountability (Accountability subscale), a with TBL subscale). Total scores reflected moderate to high higher preference for TBL than lecture (Preference for TBL levels of favorable experiences with TBL. or Lecture subscale), and satisfaction with TBL (Satisfaction

Table 2. Summary of HESI ${ }^{\circledR}$ Management scores, critical thinking, leadership and management skills, overall course experience, and TBL-SAI subscale scores and total scores

\begin{tabular}{llll}
\hline & $\begin{array}{l}\text { Spring 2014 (N = 119) } \\
\text { M (SD) }\end{array}$ & $\begin{array}{l}\text { Summer 2015 (N = 102) } \\
\text { M (SD) }\end{array}$ & $\begin{array}{l}\text { Difference Between } \\
\text { Groups }\end{array}$ \\
\hline Academic Performance & $\mathrm{N}=119$ & $\mathrm{~N}=102$ & \\
HESI $^{\circledR}$ Management Score & $760(153.77)$ & $812(136.57)$ & $t=12.64 ; p<.01$ \\
End-of-Semester Course Evaluations & $\mathrm{N}=35$ & $\mathrm{~N}=26$ & \\
Critical Thinking & $\mathrm{M}=2.67(1.16)$ & $\mathrm{M}=3.38(0.85)$ & $t=2.76 ; p=.01$ \\
Leadership and Management Skills & $\mathrm{M}=2.5(1.21)$ & $\mathrm{M}=3.56(0.70)$ & $t=4.33 ; p<.01$ \\
Overall Course Experience & $\mathrm{M}=2.66(.91)$ & $\mathrm{M}=3.78(0.42)$ & $t=6.45 ; p<.01$ \\
TBL-Student Assessment Instrument & - & $\mathrm{N}=43$ & \\
Accountability & -- & $\mathrm{M}=33.33(3.73)$ & - \\
Preference & -- & $\mathrm{M}=56.67(11.06)$ & - \\
Learner Satisfaction & -- & $\mathrm{M}=36.02(8.05)$ & - \\
Total Score & -- & $\mathrm{M}=126.02(12.77)$ & -- \\
\hline
\end{tabular}

Note. HESI $^{\circledR}=$ Health Education Systems Incorporated, $\mathrm{M}=$ Mean, $\mathrm{SD}=$ standard deviation

\section{Discussion}

The research hypothesis that learners in the TBL course would perform significantly better than learners in the instructor-led, lecture-based course was supported as demonstrated by significantly higher HESI ${ }^{\circledR}$ Management scores and self-reported measures of critical thinking, leadership and management skills, and overall course ratings. The hypothesis that learners in TBL would report high levels of accountability was partially supported with learners reporting a moderate to high degree of accountability. Learners in TBL reported a preference and satisfaction with the TBL approach, which demonstrates TBL as an acceptable method for teaching undergraduate nursing students. Findings on accountability are important, because a lack of accountability clearly limits individual learning and team preparedness. Because the quality of the individual work and teamwork was monitored (by grades), the readiness assurance process may have improved learners' accountability, and these findings translated to significantly better academic performance and greater perceived benefit in the TBL course than in the lecture-based course.

The importance of working effectively in a team is essential to health care and patient safety. Medical errors caused by lack of communication are pervasive in today's complex health care systems and can lead to tragic consequences for patients. ${ }^{[18]}$ TBL prepares the health care workforce to work in teams, synthesize evidence, and communicate with pa- tients to provide safe and effective patient care. With this approach, teams focus on decision-making and problemsolving skills that promote effective communication, collaboration, and teamwork, all of which prevent errors. ${ }^{[18]}$ Last, incorporating meaningful professional competencies that develop collaborative attitudes and skills is challenging in modern health professional training; thus, TBL is a useful approach to develop and document collaborative attitudes and skills. ${ }^{[19]}$

\section{Conclusion}

Although the authors found the TBL methodology was significantly better than traditional faculty-led lecture in academic and self-reported skills and attitudes, the faculty had been formally trained and had refined the course before implementing the research project. Preparing a TBL course requires significant time and planning because each activity is linked to the next with explicitly designed assignments. ${ }^{[16,20]}$ However, TBL is feasible in nursing education because it requires no extra facilities or faculty. Strategies of successful TBL include: (1) properly formed and managed groups, (2) student accountability, (3) team assignments that promote learning, group interaction and team development, and (4) frequent and immediate feedback to learners. ${ }^{[16]}$ Implementation of TBL involves planning before class, forming groups in the first class and reminding the learners of the learning objectives, applying the content, and engaging in teamwork. The role of the faculty member in TBL is that of a facilitator who 
guides and encourages learners to articulate their understanding and the rationale for their answers, which is a different role than the faculty member in an instructor-led lecture who synthesizes and delivers expert content. ${ }^{[21]}$ Thus, the education of faculty on the TBL methodology is important for the successful implementation of TBL.

The strategic emphasis on inter-professional collaboration ${ }^{[2]}$ affirms the need for future implementation and evaluation of TBL among inter-professional health care learners, which replicates real-world clinical practice. To control for extraneous factors and limit confounding, future research should evaluate the effectiveness of TBL via a randomized control trial.

\section{Conflicts OF InTEREST Disclosure}

The authors declare that there is no conflict of interest.

\section{REFERENCES}

[1] Patient Protection and Affordable Care Act, 42 U.S.C. $§ 18001.2010$. Available from: http://www.hhs.gov/healthcare/rights/la w/patient-protection.pdf

[2] World Health Organization. Framework for action on interprofessional education and collaborative practice. Geneva: Switzerland 2010. Available from: http://www.who.int/hrh/resources/ framework_action/en/

[3] Benner P, Sutphen M, Leonard V, et al. Educating nurses: A call for radical transformation. San Francisco, CA: Jossey-Bass; 2010.

[4] Fink L, Parmelee D. Preface. In L. Michaelsen, D. Parmelee, K.McMahon, \& R. Levine (Eds.), Team-based learning for health professions education: A guide to using small groups for improving learning (pp. xi-xv). Sterling, VA: Stylus; 2008.

[5] Billings DM, Halstead JA. Teaching in nursing: A guide for faculty (4th ed.). St. Louis, MO: Elsevier Saunders; 2011.

[6] American Association of Colleges of Nurses. The essentials of baccalaureate education for professional nursing practice. 2008 Available from: http://www.aacn.nche.edu/publications/o rder-form/baccalaureate-essentials

[7] Quality and Safety Education for Nurses. (n.d.) Pre-Licensure KSAS 2015. Available from: http://qsen.org/competencies/pre-1 icensure-ksas/

[8] Institute of Medicine. The future of nursing: Leading change, advancing health. 2015. Available from: http://books.nap.edu/ openbook $\cdot$ php?record_id $=12956 \&$ page $=R 1$

[9] American Nurses Credentialing Center. Magnet Recognition Program ${ }^{\circledR}$. 2014. Available from: http://www.nursecredent ialing.org/magnet. aspx

[10] American Association of Critical Care Nurses. Beacon Award for Excellence handbook. 2010. Available from: http://www . aacn.o $\mathrm{rg} / \mathrm{wd} /$ beaconapps/docs/beacon-handbook.pdf

[11] Michaelsen LK, Parmelee DX, McMahon KK, et al. Team-based learning for health professions education: A guide to using small groups for improving learning. Sterling, VA: Stylus Publishing; 2007.

[12] Mennenga HA. Student engagement and examination performance in a team-based learning course. Journal of Nursing Education. 2013;
52(8): 475-479. PMid:23855344 http://dx.doi.org/10.3928 /01484834-20130718-04

[13] Sisk RJ. Team-based learning: Systematic research review. Journal of Nursing Education. 2011; 50(12): 665-669. PMid:22007709 http://dx.doi.org/10.3928/01484834-20111017-01

[14] Kalaian SA, Kasim RM. A meta-analytic review of studies of the effectiveness of small-group learning methods on statistics achievement. Journal of Statistic Education. 2014; 22(1): 1-20. Available from: http://www.amstat.org/publications/jse/v2 2n1/kalaian.pdf

[15] Epstein ML, Lazarus AD, Calvano TB, et al. Immediate feedback assessment technique promotes learning and corrects inaccurate first responses. The Psychological Record. 2002; 52: 187-201.

[16] Michaelsen L, Sweet M. Chapter 2: Fundamental principles and practices of team-based learning. In L.K. Michaelsen, Parmelee, D, McMahon, K. \& Levine, R. (Eds.), Team-based learning for health professions education. Sterling, Virginia: Stylus Publishing; 2008. 9-34 p.

[17] Mennenga HA. Development and psychometric testing of the TeamBased Learning Student Assessment Instrument. Journal of Nursing Education. 2012; 37(4): 168-72. PMid:22688878 http://dx.doi . org/10.1097/NNE. 0b013e31825a87cc

[18] O'Daniel M, Rosenstein A. Chapter 33: Professional communication and team collaboration. In R.G. Hughes (Ed.), Patient Safety and Quality: An evidence-based handbook for nurses. 2008. Available from: http://www.ncbi.nlm.nih.gov/books/NBK2637/

[19] Parmelee D. Chapter 1: Team-based learning in health professions education: Why is it a good fit? In L.K. Michaelsen, Parmelee, D, McMahon, K. \& Levine, R. (Eds.), Team-based learning for health professions education. Sterling, Virginia: Stylus Publishing; 2008.

[20] Clark M. Chapter 13: Using team-based learning as a substitute for lectures in a required undergraduate nursing course. In L.K Michaelsen, Parmelee, D, McMahon, K. \& Levine, R. (Eds.), Teambased learning for health professions education. Sterling, Virginia: Stylus Publishing; 2008. 151-160 p.

[21] Pelley J, McMahon K. Chapter 8: Facilitator skills. In L.K. Michaelsen, Parmelee, D, McMahon, K. \& Levine, R. (Eds.), Teambased learning for health professions education. Sterling, Virginia: Stylus Publishing; 2008. 151-160 p. 